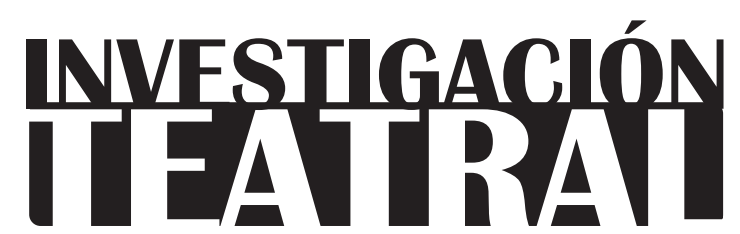

Revista de artes escénicas y performatividad

Vol. 12, Núm. 19

abril-septiembre 2021

Segunda época

ISSN impreso: $1665-8728$

ISSN electrónico: 2594-0953

Universidad Veracruzana

\title{
El teatro como ejercicio terapéutico en Todos somos el rey Lear, de Guillermo Schmidhuber
}

\author{
Lourdes Betanzos"
}

\footnotetext{
* Auburn University, Estados Unidos. e-mail: betanlo@auburn.edu
}

Recibido: 05 de octubre de 2020

Aceptado: 01 de febrero de 2021

Doi: $10.25009 /$ it.v12i19.2669 


\title{
El teatro como ejercicio terapéutico en Todos somos el rey Lear, de Guillermo Schmidhuber
}

\section{Resumen}

En Todos somos el rey Lear, el dramaturgo mexicano Guillermo Schmidhuber de la Mora plantea un claro ejercicio intertextual con William Shakespeare. El presente estudio es una exploración de cómo Schmidhuber teatraliza la creación de hiperrealidad como proceso terapéutico no sólo para ciertos personajes de la obra, sino también para el público e, incluso, para el dramaturgo mismo. Se emplean los conceptos de Jean Baudrillard sobre la hiperrealidad y el simulacro, las afirmaciones del mismo Schmidhuber sobre la dramaturgia, así como también los conceptos psicológicos de Phil Jones sobre la drama-terapia y los efectos transformativos de este ejercicio teatral. Por medio de este proceso que resulta terapéutico, los personajes de la obra intentan enmendar los conflictos vitales que los inquietan a, a la par que el autor mismo negocia su identidad como dramaturgo.

Palabras clave: hiperrealidad; simulacro; terapia; intertextualidad; dramaturgia; metateatro.

\section{Theather as therapeutic exercise in We are all King Lear from Guillermo Schmidhuber}

\begin{abstract}
In We Are All King Lear, Mexican playwright Guillermo Schmidhuber de la Mora clearly lays out an intertextual exercise with William Shakespeare's work. This essay explores how Schmidhuber dramatizes the creation of hyperreality as a therapeutic process not only for certain characters of the play, but also for the audience and even for the playwright himself. To carry out this exploration, the paper applies Baudrillard's concepts of hyperreality and simulation, as well as some affirmations from Schmidhuber himself about dramaturgy, and some of Phil Jones' psychological concepts regarding drama therapy and its transformative effects as a theatrical exercise. Through this therapeutic process, the play's characters attempt to rectify the vital conflicts that unsettle them, while the author himself negotiates his identity as a playwright.
\end{abstract}

Keywords: hyperreality; simulation; therapy; intertextuality; dramaturgy; metatheater. 


\section{El teatro como ejercicio terapéutico en Todos somos el rey Lear de Guillermo Schmidhuber}

El teatro no es un pasatiempo, es una búsqueda conjunta del autor, el director, los actores y el público de una verdad interior. Guillermo Schmidhuber, Todos somos el rey Lear

$\mathrm{E}$ n su obra Todos somos el rey Lear, escrita en 1979 y publicada en 1982, Guillermo Schmidhuber plantea una clara intertextualidad con William Shakespeare, comenzando con el título de su obra y extendiéndose hasta la escenificación de la obra de Shakespeare dentro de su trama. A pesar de ser una de las obras tempranas del dramaturgo mexicano, hasta la fecha no ha recibido estudio profundo, con la única excepción de un párrafo que le dedica Ronald Burgess en el libro The New Dramatists of Mexico 1967-1985. En la obra de Schmidhuber, una compañía teatral ensaya, improvisa y representa la obra El rey Lear de William Shakespeare. Mientras tanto, los cambios de papel de cada personaje contribuyen a borrar los límites entre realidad y simulación o ficción, al establecerse una similitud entre el contexto y la trama de la obra de Shakespeare y los de la obra de Schmidhuber. En esta última es evidente un contexto de simulacro y de creación de una hiperrealidad. De esta manera, el dramaturgo propone un tertium comparationis, el punto común en el ejercicio comparativo entre la obra de Shakespeare y la propia.

Sin embargo, la obra de Schmidhuber va más allá del tertium comparationis, ya que las comparaciones sacadas por los personajes que crean hiperrealidad funcionan para éstos como un proceso terapéutico, como también para el dramaturgo en el ejercicio de escribir la obra. Se identifica aquí dicho proceso terapéutico con el acto creativo dramatúrgico que ejercen tanto 
los personajes de la obra de Schmidhuber como el autor mismo. Para examinar este proceso, se emplearán los conceptos de Jean Baudrillard relativos a su propuesta de las cuatro etapas del simulacrum, como también se incluirán conceptos de drama-terapia de Phil Jones y afirmaciones del mismo Guillermo Schmidhuber sobre la escritura de esta obra.

El presente estudio es una exploración de cómo Schmidhuber teatraliza esta comparación por medio del simulacro, haciéndola funcionar no sólo como forma de resolver relaciones interpersonales de los personajes, en particular las filiales, sino también como una búsqueda de identidad como dramaturgo. Por medio de este proceso, los personajes Millonario verdadero y Álvaro intentan enmendar los conflictos vitales que inquietan a ambos (cabe acotar que hay dos personajes cuyos papeles son actuados por dos actores distintos: Millonario y Millonario verdadero. Tanto en la nomenclatura original como en este trabajo, Millonario se refiere al primero que aparece en la obra, y Millonario verdadero, al que entra hacia el final).

En la obra del autor isabelino, el rey Lear, con la intención de heredar su reino a sus tres hijas, las somete a prueba, aunque este plan fracasa y él es abandonado por ellas. A pesar de los esfuerzos de quienes mantienen su lealtad al rey, Lear llega a reconocer tardíamente que debería haberle dejado la herencia a su hija Cordelia, la única que se redime al ayudar a Kent y Edgar a salvar y curar a Lear cuando éste está simbólicamente ciego al no reconocer sus propias fallas hasta demasiado tarde. Esta trama sirve de punto de partida en la obra del dramaturgo mexicano, donde Millonario verdadero equivale a Lear y los demás personajes aparecen como actores en la trama, quienes cambian intermitentemente a representar personajes de la obra de Shakespeare o de las invenciones de la imaginación de Millonario. Este último adopta el papel de director después de ser público exclusivo de la escena que abre Todos somos el rey Lear.

Jean Baudrillard mantiene que uno puede vivir con la idea de una verdad distorsionada (5). Explica que esto consiste en sustituir lo real por signos que sugieren o simulan la realidad, o sea simulacros (2). Además, Baudrillard afirma: "Lo que toda sociedad busca al seguir produciendo, y sobre-produciendo, es restaurar lo real que se le escapa” (23). ${ }^{1}$ Con este proceso, alude a la creación de una hiperrealidad por medio de la simulación, a la cual describe como una semblanza alucinatoria de la realidad misma (ibídem). Para sintetizar el presente marco teórico, la simulación es un esfuerzo del individuo para recuperar la realidad efímera, la cual requiere improvisación o simulacro continuo. Es más, este proceso de fusión o disolución de la realidad y la ficción constituye una estrategia dramática, cuyo propósito terapéutico le permite al simulador mayor comprensión de la condición humana.

1 What every society looks for in continuing to produce, and to overproduce, is to restore the real that escapes $i t$. Todas las citas cuyo idioma original no es el español fueron traducidas por la autora del presente artículo y en algunos casos corregidas en el proceso editorial. 
Este ejercicio terapéutico teatral se manifiesta en la obra de Schmidhuber a través del personaje de Álvaro y quienes le ayudan a llevarlo a cabo, la mayoría de los cuales son actores ensayando y representando El rey Lear de William Shakespeare. El ejercicio teatral de la obra de Schmidhuber se puede dividir conforme a las cuatro etapas de representación que define Baudrillard: (1) la realidad, (2) la realidad distorsionada, (3) la realidad fingida y (4) la ausencia de realidad.

Como terapia psicológica, Phil Jones identifica tres procesos claves de la drama-terapia en Drama as Therapy: proyección dramática, transformación y juego. ${ }^{2}$ Jones define la proyección dramática como lo que ocurre cuando el individuo se involucra emocional e intelectualmente en el enfrentamiento de asuntos llevados a terapia por medio de formatos dramáticos. La transformación describe la manera en que cambia la experiencia del individuo en relación con los problemas expresados. El juego es una de las maneras de experimentar o acercarse a un problema, en la cual se crea un espacio donde el individuo puede probar los temas sin consecuencia alguna (10).

Para captar este proceso en la obra de Schmidhuber es necesario comprender el flujo de su trama y explicar los planos temporales que la componen. El dramaturgo mismo describe la estructura de esta obra como "las cajitas chinas: teatro dentro del teatro dentro del teatro" (Trece apuestas 156). Tiene rasgos de metateatro de la representación, lo cual ha llegado a ser una característica distintiva de la dramaturgia de Schmidhuber, como lo hemos señalado Olga Marta Peña Doria y la autora del presente estudio en Volición y metateatralidad: La dramaturgia de Guillermo Schmidhuber y Sueños: Aproximaciones a la dramaturgia de Guillermo Schmidhuber, respectivamente.

En la obra de Schmidhuber primero está lo que esta autora denomina el marco teatral implicado, que consiste en el ensayo que está en curso al inicio de Todos somos el rey Lear llevado a cabo por los personajes-actores con nombres propios. Segundo, está el plano metateatral, donde se ubica la representación de El rey Lear de Shakespeare. Le sigue un segundo plano metateatral, que corresponde a la adaptación de la obra de Shakespeare y la creación de una hiperrealidad por parte de Millonario verdadero. Sin embargo, como se comprueba al final de la obra, éste no es el único nivel de hiperrealidad en ella. Hay además un segundo nivel hiperreal, correspondiente a cuando Álvaro-anciano indica haber creado el anterior plano hiperreal como actor y dramaturgo textual. A este último plano se le llamará marco hiperreal, y es ahí donde Álvaro-anciano y Schmidhuber mismo ejercen una reflexión sobre el proceso creativo de la dramaturgia. Véase la Figura 1 que ilustra los diferentes planos de representación en correspondencia con las etapas concebidas por

2 dramatic projection, transformation, and play. 
INVESTIGACIÓNTEATRAL

Revista de artes escénicas y performatividad

Vol. 12, Núm. 19

abril-septiembre 2021
El teatro como ejercicio terapéutico en Todos somos el rey Lear, de Guillermo Schmidhuber

Lourdes Betanzos

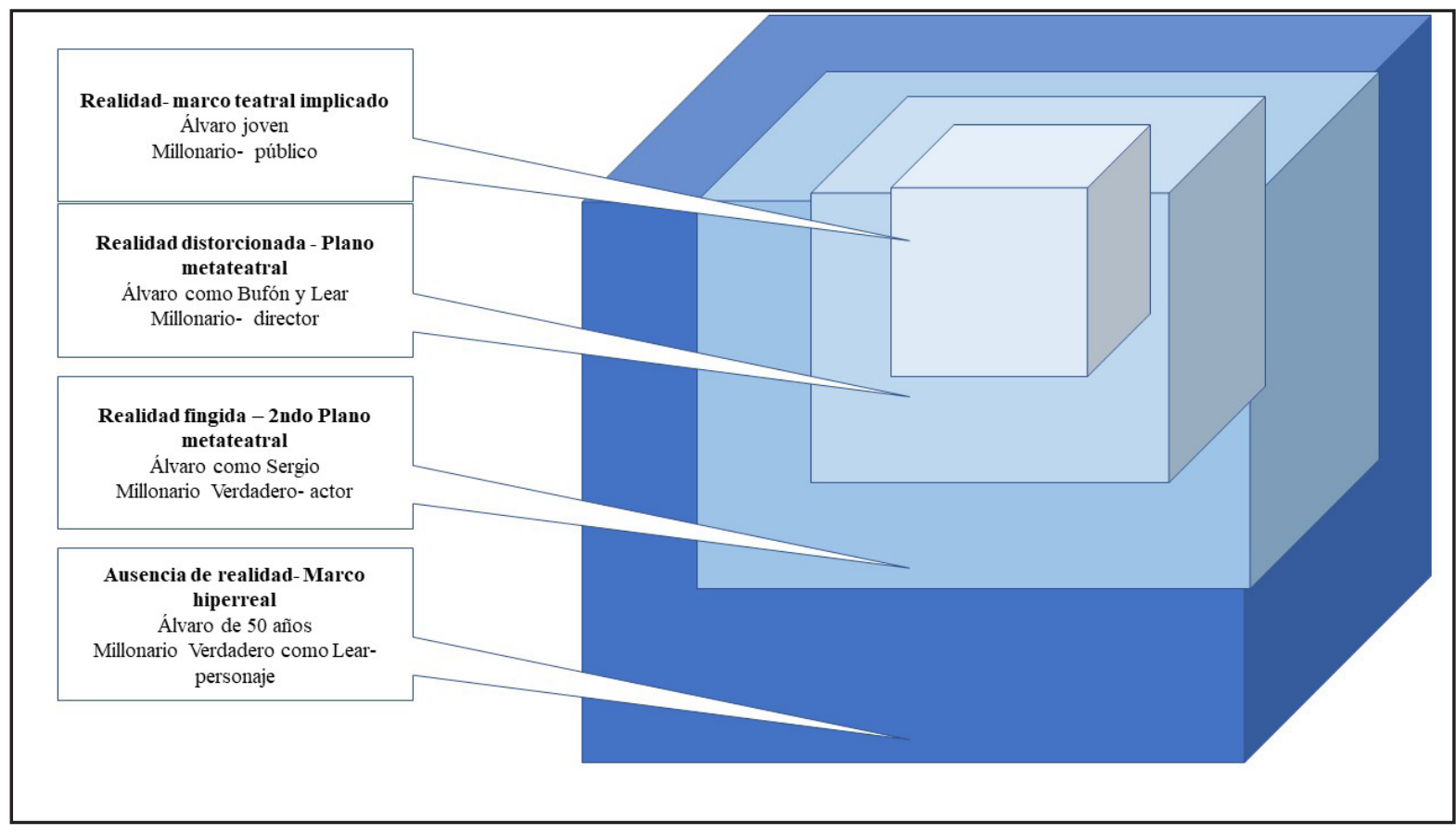

Figura 1. Planos de representación organizados a través de cajas chinas. Fuente: elaboración propia.

Baudrillard, a la vez que, con la identificación de los papeles de Millonario, Millonario verdadero y Álvaro, organizada mediante las “cajas chinas” antes mencionadas.

La retórica empleada en la apertura de la obra, con el parlamento de Álvaro, guarda semejanza con los parlamentos retóricos que iniciaban las obras durante la época en que escribió Shakespeare y funciona para establecer el marco teatral de la obra. También revela que la temática de la obra es, en las palabras del personaje/actor Álvaro, "un novedoso análisis de $E l$ rey Lear, de William Shakespeare” y que “[d]etrás de la trama se esconde una pregunta: ¿Qué significa hoy el teatro para la humanidad? ¿Mucho...? ¿Poco...? ¿Nada...? Ustedes mismos tendrán que responder a esa pregunta" (Schmidhuber, Trece apuestas 156). De esta manera se plantea uno de los temas de la obra que incluye la exploración de la esencia del teatro mismo, esbozándose un contexto de reflexión al respecto. En su libro El ojo teatral, Schmidhuber indica cómo entiende la dramaturgia y el teatro:

Dramaturgia es el proceso de teatralizar la vida humana mediante la abstracción de sus elementos; es un proceso cognoscitivo que conlleva el énfasis de algunos de sus elementos y la supresión de otros. Consiste en observar la vida enmarcada por 
sus circunstancias límites, dentro de un espacio rarificado y bajo un péndulo descompensado que puede acelerar las horas o detener los segundos. El teatro convierte la existencia humana en un vivir artificial, lo que permite modificar las limitaciones humanas (13).

Con las afirmaciones anteriores, Schmidhuber sugiere el aspecto de simulacro de la dramaturgia, como también el carácter terapéutico que dicho acto creativo puede poseer al hacer referencia a un "espacio rarificado" y un "vivir artificial", los cuales abren la posibilidad de cambiar "las limitaciones humanas" (ibídem). Aquí cabe hacer referencia a la proyección dramática en el proceso psicológico de la drama-terapia, que Jones define como:

[...] el proceso por el cual los clientes proyectan aspectos de sí mismos o de su experiencia en materiales teatrales o dramáticos o en la escenificación, externalizando así sus conflictos interiores [...] La expresión dramática posibilita el cambio a través de la creación de perspectiva, junto con la oportunidad para la exploración y la toma de consciencia (insight) por medio de la representación de la materia proyectada (84). ${ }^{3}$

Schmidhuber indica que la temática de Todos somos el rey Lear va más allá de una breve exploración del género dramático para incluir una indagación en la naturaleza humana -con respecto a su capacidad de tomar decisiones a pesar del riesgo- y el papel que tiene el teatro en ella como medio de exploración introspectiva. La nota a pie de página que el dramaturgo incluye al principio de Todos somos el rey Lear presenta la temática como "una meditación dramática sobre la verdadera naturaleza del Teatro", y afirma que el ejercicio teatral envuelve "el arte de la decisión, el riesgo y el errar" (Trece apuestas 156). Como queda implícito en estas palabras y como se desarrollará más adelante en el presente estudio, Schmidhuber explora con esta obra su propia identidad como dramaturgo. Así, aplica la proyección dramática que, según las teorías de Phil Jones, suele inspirar la actividad creativa (Drama as Therapy 137).

El marco implicado en los momentos iniciales de la obra, cuando Álvaro es joven y forma parte de la compañía teatral que se encuentra ensayando, da pie a un contexto o una situación que resultará defectuosa, ya que -como se da cuenta el lector o espectador- hay inconsistencias entre el diálogo y los signos visuales que ofrecen los actores/personajes,

3 [...] the process by which clients project aspects of themselves or their experience into theatrical or dramatic materials or into enactment, and thereby externalize inner conflicts. [...] The dramatic expression enables change through the creation of perspective, along with the opportunity for exploration and insight through the enactment of the projected material. 
además de que la escena misma sugiere que hay algo mal o existe alguna falsedad en la acción que toma lugar en el escenario. Aun la acotación que describe la entrada del primer personaje implica cierto nivel de nerviosismo de su parte al indicar que "se le nota un tanto intranquilo" (Trece apuestas 156). Mauricio es caracterizado como impaciente y un tanto airado (Trece apuestas 157). Otro indicio de un contexto imperfecto es que, al principio de la obra, cuando los actores declaman textos de El rey Lear de Shakespeare mientras comen, lo hacen sin adoptar plenamente los papeles, mecánicamente y sin interés (Trece apuestas 160-162). Además, la escenografía y la utilería dan un sentido de estancamiento, resultando "ser de mal gusto y estar elaborada[s] con pobreza; hay algo en ella[s] que recuerda esas fotografías de antiguas puestas en escena, que más que dar una impresión de vida, hacen pensar en muertos embalsamados y olores acres" (Trece apuestas 157). Las desconexiones entre los signos verbales y los visuales plantean la posibilidad de la creación de una realidad virtual, ya que desde el comienzo el espectador/lector sabe que la trama no ocurre en un teatro sino en un hotel de provincia. Esto establece la existencia de un espacio propicio para el proceso terapéutico, a la vez que afirma su necesidad.

Dicho espacio, oportuno para la proyección dramática, permite una manera distinta de entender el contexto real. La diferencia del diálogo de la metarepresentación de los textos de Shakespeare, de los planos 1 y 2 metateatrales, con respecto al del marco implicado e hiperreal, es palpable aun en el lenguaje empleado en cada uno. En estas representaciones de los planos metateatrales se utiliza castellano antiguo y formal típico de la época del dramaturgo isabelino, evocando así el contexto británico contemporáneo a esa época (Trece apuestas 160-162). Mientras tanto, el lenguaje del marco implicado es una mezcla de discurso entre actores y lenguaje conversacional de hoy en día. Al concluir la primera escena del Lear renacentista abruptamente, con la exclamación de “AAlto!” de Millonario, comienza un momento en el que la ficción y la realidad se mezclan en un intercambio entre Sergio, María y Millonario. En dicho intercambio, este último le pregunta a María - quien acaba de declamar en el papel de Gonerilda, hija de Lear-, “¿Quieres a tu padre?”, lo que provoca la respuesta: “¿A mi padre o al de Gonerilda?” (Trece apuestas 162). Esto da lugar a la apertura y creación del plano 2 de la representación, o el plano de la hiperrealidad creada por Millonario. Se alterna entre el marco implicado y el plano 2 hasta llegar al punto de confusión entre los dos niveles. Otro ejemplo de esto se encuentra más adelante en el intercambio entre Millonario, María-Gonerilda y Esmeralda-Regania:

Millonario: [Colérico.] ¿Crees que no sabías qué hacer con ellos? ¡Ilusa! [Corrige.] Lear pudo haber tirado sus bienes a la calle, ahí hay gente que siempre necesita algo.

ESMERALDA-REgANIA: Tanto como yo. 
Millonario: [Fatuo.] Tú no requieres dinero, en toda tu vida no te acabarías lo que se te ha dado.

MARÍA-GONERILDA: [Atacando abiertamente.] ¡Nada nos diste! ¡Todo era nuestro! Millonario: ¡Mentira! ¡Mentira! Hablas como Florencia. [Señaló a Esmeralda y se dio cuenta que habló de más.]

ESMERALDA-REGANIA: Yo no soy Florencia; me llamo Esmeralda y represento a Regania. MILlonARIO: [Con gran ira.] ¡Todas las hijas son iguales!

MARÍA: [Con astucia.] Florencia debe ser una buena mujer (Trece apuestas 166).

Este intercambio muestra que Millonario vacila hacia el plano 2, hasta que María le aclara su identidad verídica. Similar ofuscación ocurre también en el texto de Shakespeare, cuando Goneril y Lear conversan: él se cae y parece padecer de amnesia. Tal confusión de nombres o lapso de memoria se repite en el acto 4 o 5 , en un intercambio con Cordelia. Como indica Phil Jones, "[l]a proyección suele ser la inspiración de la actividad creativa" (137). ${ }^{4}$ Aquí, la alternación entre los planos de realidad e hiperrealidad es la manifestación de la actividad creativa de la dramaturgia.

La transición entre el plano metateatral y el segundo plano metateatral se inicia cuando Millonario se interesa por la escena del tribunal en el texto de Shakespeare (Trece apuestas 163); sin embargo, después de que los actores recitan esta parte, Millonario se desilusiona con la conclusión del juicio y se entabla una discusión acerca de cómo él podría adaptar el texto clásico (Trece apuestas 165). Esta discusión pasa hacia un intercambio entre Esmeralda-Regania y Millonario-Lear, donde éste confunde su identidad y vida real con las de Lear, en el plano 2 metateatral. En el momento que la actriz Esmeralda y Millonario discuten sobre la herencia del Lear de Shakespeare, se implica que Florencia es la hija real de Millonario, ofuscándose así la división entre planos de representación. Esmeralda dirige luego una crítica hacia Millonario, que pasa desapercibida por él. La actriz le comparte: "soy feliz, no tengo que recurrir a parodias teatrales para poder hablar con mi hija" (Trece apuestas 167). Aquí se halla una verdad revelada sobre el proceso terapéutico de la teatralización de la dinámica padre/hija. Como elabora Jones, en la dramaterapia los individuos pueden adoptar el papel de un personaje ficticio y de esta manera proyectar rasgos de sí mismos en el contexto dramático: "[se] crea un teatro en miniatura dentro del grupo y dentro de uno mismo" (83). En esta escena de la obra de Schmidhuber, Millonario es quien proyecta su deseo paternal por comunicarse con su hija al adoptar el papel de Lear.

4 Projection is often the inspiration for creative activity.

5 A miniature theater is created within the group and within the self. 
Millonario también sugiere este proceso, cuando afirma: "La poesía sólo sirve para ablandar la voluntad y el teatro para nublar el entendimiento" (Trece apuestas 169). De esta forma, el teatro se destaca como instrumento que, por lo menos, inquieta a la mente. Según el autor de Drama as Therapy:

La producción de una obra teatral incluye la noción de la interpretación de un texto. Como señala Esslin en Anatomy of Drama (1978: 88), los espectadores son atraídos al teatro en parte para ver la interpretación particular que un actor o director lleva a un texto determinado. Así, en la drama-terapia el interés en el trabajo proyectivo con un texto depende de un proceso semejante al del trabajo interpretativo ejercido por un director o actor. El interés se halla en las maneras en que el cliente puede usar el texto como un material en el cual proyectar sus preocupaciones internas para emplearlo como medio de auto-exploración. (Jones, 153) ${ }^{6}$

Al decir que el teatro sólo sirve para "nublar el entendimiento", Millonario establece su desconfianza en las propiedades terapéuticas, porque éstas revelan precisamente la versión de la realidad que él no desea enfrentar. Él no confía en el teatro por tal motivo. Por contraste, en la obra shakespeariana, Lear sugiere que, para mejor acercarse a la situación que enfrenta, se necesitan espejuelos o lentes correctivos: "Ponte los anteojos; / Y, como vil político, muestre ver lo que no ve" (Shakespeare, 1002). ${ }^{7}$ A tal afirmación puede aplicarse el concepto de hiperrealidad, al notar que Lear recomienda ver los asuntos de una manera distinta para vislumbrar aquello que parecía no poderse ver anteriormente. Es precisamente lo antes no visto (o comprendido), lo que compone la hiperrealidad. Como señala Edgar, de El rey Lear, en su locura ha hallado la razón: "O, ¡tema e impertinencia mezclados! ¡Razón en la locura!” (ibídem). ${ }^{8}$ Es en la creación de esta hiperrealidad que se halla claridad, aun en la obra de Schmidhuber y pese a que el partícipe de su gestación, Millonario, no crea en sus funciones beneficiosas. Son el público y el dramaturgo de Todos somos el rey Lear quienes hallan dicha claridad. Esto sugiere el valor transformativo de la drama-terapia des-

6 Theatrical play production includes the notion of interpretation of a text. As Esslin point out in An Anatomy of Drama (1978:88), audiences are drawn to plays in part to see the particular interpretation an actor or director brings to a given text. So in dramatherapy interest in projective work with a text relies on a process akin to the interpretive work undertaken by a director or actor. The interest lies in the ways that the client can use the text as material in which to project their inner preoccupations, in order to use it as a means of self-exploration".

7 Get thee glass eyes; / And, like a scurvy politician, seem / To see the things thou dost not.

$8 \quad$ O, imatter and impertinency mix'd! Reason in madness!". 
crita por Phil Jones, quien afirma: "El proceso de estar envuelto en hacer teatro, la potencial satisfacción creativa de la representación, pueden ser transformativos" (121). ${ }^{9}$

En la obra hay una serie de claves que sugieren la intervención de personajes del marco implicado en la creación del nivel hiperreal de Millonario, en plano 2. Un ejemplo es el intercambio entre Millonario y María, donde ella afirma que comprende a Lear, "el Lear solitario" (Trece apuestas 170). Luego, en el mismo intercambio, a Millonario se le quiebra la voz y declara: "no sé qué hacer"; María responde: "Yo intuyo que puedo ayudarlo" (ibídem), entablando aun otro nivel de representación al entrar en el papel de Gonerilda. Pero esta vez con claras intenciones de ayudar a Millonario a resolver su inquietud por medio de un proceso de simulación. Ella le aclara a Millonario:

Yo no me voy. Usted necesita hablar con alguien. Yo soy Gonerilda. Cuando mi padre, el Rey Lear, me dio poder, perdí el equilibrio en mi vida, porque nunca obtuve una respuesta en la búsqueda del sentido de mi existencia, y llegué a olvidar mis deberes de esposa y madre, y busqué el amor de otro hombre, el mismo que mi hermana amaba, y acabé matándola y matándome (Trece apuestas 170).

Con estas declaraciones hipotéticas sobre el personaje de Shakespeare, María-Gonerilda le ofrece a Millonario una explicación de los efectos que tuvo el poder que él le dio a ella. Al darse cuenta de que la situación de sus hijas es similar a la de las hijas de Lear, Millonario declara: “¡Yo no quiero que mis hijas acaben como las de Lear!” (Trece apuestas 170). Aquí, por medio del nivel hiperreal del plano 2, Millonario reconoce la falla de su relación con sus hijas Estela y Florencia, a quienes dejó administrar su herencia en vida. Por medio de esta creación de simulacro con los textos de Shakespeare, Millonario acepta que tal decisión de parte suya fue un error (Trece apuestas 171). Sin embargo, a diferencia de los personajes de la obra isabelina, Millonario todavía está a tiempo de enmendar su error si emplea procesos teatrales para hallar el vínculo entre las emociones o experiencias vitales y la exteriorización dramática. Los conceptos sobre la proyección dramática mantienen que: "Las formas y los procesos dramáticos, ya sea al jugar con objetos o desempeñar un papel, conectan la expresión externa del teatro con las emociones interiorizadas o las experiencias de vida" (Drama as Therapy 83). ${ }^{10}$

Durante la misma conversación con María, Millonario revela cómo llegó a comprender su conflicto: "Hace unos días vi la puesta en escena de El Rey Lear con su compañía, y fue

9 The process of being involved in making drama, the potential creative satisfaction of enactment, can be transformative.

10 Dramatic forms and processes, whether playing with objects o playing roles, connect outer expression in drama with inwardly held feelings or life experiences. 
como un golpe seco. Volví todos los días, tarde y noche, pero no he alcanzado a entender mi error, aunque sé que es el mismo del rey Lear. [Sincero.] ¡Ayúdenme a encontrar la verdad!" (Trece apuestas 172). María le aconseja: "Busque a su hija Caridad; en ella está su salvación" (ibídem). Luego, Margot-Cordelia recita parlamentos del texto de Shakespeare que corresponden a la situación entre Millonario y su hija Caridad, como por ejemplo cuando enuncia: “iMi querido padre! Por ti mi duelo ha entristecido a Francia, y mis inagotables lágrimas han excitado su piedad. No arma nuestras manos la loca ambición, sino el amor [el Millonario se enternece], el tierno amor a un padre anciano y querido. Vamos a combatir en defensa de tus derechos. ¡Cuánto me tarda el verte y el oír tu voz!” (ibídem). En este intercambio entre Millonario y María con el complemento de las recitaciones de Margot-Cordelia, Millonario continuamente se refiere a Margot-Cordelia como Caridad, su hija real, hasta pedir que venga a sus brazos, ofuscando así la división entre realidad y ficción, niveles ambos que son performativos. El proceso sugerido en esta escena concuerda con las ideas de Baudrillard, quien mantiene que no se trata de imitación, ni duplicación, ni parodia, sino de una substitución de lo real por los signos de lo real (2). En el caso de esta escena en la obra de Schmidhuber, se propone que se sustituya la realidad de Millonario por los signos correlativos de la obra de Shakespeare. En el contexto de la drama-terapia se establece un vínculo entre la realidad y la representación dramática de la siguiente manera:

La representación dramática y la exploración en la dramaterapia se pueden describir como una reorganización, un reordenamiento de materia. [...] Visto de esta manera, un cierto número de transformaciones ayudan a que el cambio ocurra en la dramaterapia $[\ldots]$

Las experiencias y los procesos que ocurren dentro de la dramaterapia se pueden entender como propiciatorios del cambio, por medio de ofrecer transformación poniendo en contacto mutuo al teatro y a la vida. Experiencias cotidianas y maneras de ser son puestas en contacto con maneras dramáticas de percibir y enfrentar las experiencias. La experiencia vital puede ser transformada por esta realidad dramática distinta (Drama as Therapy 120-121). ${ }^{11}$

11 Dramatic representation and exploration in dramatherapy can be described as a reorganizing, a rearranging of material. [...] Looked at in this way, a number of transformations help change to occur in dramatherapy $[\ldots]$

Experiences and process which occur within dramatherapy can be understood to assist change by offering transformation through bringing drama and life into contact with each other. Everyday life experiences and ways of being are brought into contact with dramatic ways of perceiving and dealing with experiences. The life experience can be transformed by this different dramatic reality. 
Con esto, se vuelve al marco implicado y el dramaturgo pone de relieve la necesidad del ejercicio de la simulación como exploración dramatúrgica. Después de que Millonario invoca a su hija Caridad, hay una intervención del personaje Amigo del verdadero millonario lanzada desde el lugar del público ficticio presente en la representación textual (Trece apuestas 173). Tal intervención representa un cambio total del flujo y de la trama de la obra. Con ella se establece, desde el público, un "contraste entre la falsedad relativa de la primera parte y la gran veracidad que continúa [sic]" (ibidem), como está indicado en la acotación correspondiente. Y la acción pasa del marco implicado al marco hiperreal. El dramaturgo describe este momento aclarando en la acotación: "hemos abandonado el teatro caduco y, por unos minutos, incursionamos en el teatro vitalista [sic]" (ibidem).

El parlamento del Amigo del millonario en esta escena subraya la metateatralidad y el simulacro: “¡Todo es falso! ¡Todo es una farsa de mal gusto! [...] ¡Esta obra es una parodia!" (ibídem). Luego, este mismo personaje revela la supuesta falsedad de la representación en curso, dirigiéndose al público: "El que ustedes conocieron aquella noche no fue el millonario, como ustedes lo llaman, sino una persona de su confianza. La verdadera persona observaba todo detrás de un espejo" (Trece apuestas 174). Pero se revelará más tarde, hacia el final de la obra, que aun esto es falso -o, mejor dicho, simulacro- cuando el mismo personaje afirma haber sido pagado para sabotear la representación por un individuo que nunca es identificado por su nombre propio en la obra, lo cual provoca la duda en el espectador y marca la posibilidad de que se haya creado aun otra hiperrealidad.

Con la antedicha intervención del Amigo del millonario se marca la conclusión del plano 2 y se inicia la creación hiperreal de un individuo llamado Millonario verdadero, quien sale de entre el público en reacción a la calumnia ejercida por Sergio sobre su hija Caridad. Millonario verdadero interviene para intentar aclararle al público que él cree que sus derechos han sido violados: "Señores y señoras, existe el derecho de autor, pero no el derecho que impida que este hombre escriba sobre mi intimidad, como tampoco que impida al rey Lear venir a defender sus derechos" (Trece apuestas 178). Así, de nuevo se borra o complica la división entre niveles de representación. Aquí, Millonario verdadero no sólo mueve la acción hacia el plano hiperreal, sino que aboga explícitamente por el poder de crearlo. La proyección dramática le permite al individuo que la ejerce crear, descubrir e interactuar con las representaciones externas de conflictos interiores (Drama as Therapy, 140). Cuando Sergio echa en cara, ante el público, que Caridad no aceptó perdonar a su padre, Millonario verdadero intenta engañar tanto a Sergio como al público sobre su identidad: "Yo no soy el millonario, soy un actor pagado”, y es interrumpido por Sergio: “¡Eso es mentira! [...] ¡Usted fracasó y nunca tendrá reposo!" (Trece apuestas 178). Sergio comienza a comparar a Millonario verdadero con el rey Lear, señalando que éste está loco y que su hija no lo perdonará, a diferencia de la figura 
de antaño (178-179). Millonario verdadero también establece conexión con los personajes de Shakespeare, cuando en su desesperación por ser llamado "loco" dice:

¡No lo estoy! ¡A veces no pienso con la claridad de antes... pero no estoy loco! ¡Tengo miedo de perder la razón como el rey Lear! ¡Necesito tanto un poco de paz!... [Baja al lunetario.] “Mísero el hombre que se arrepiente tarde!” Está bien, usted tiene la razón, la tuvo su pieza... ¡Hablaré con Caridad! ¡Solamente ella tiene el secreto de la felicidad! ¿Por qué Lear llegó a tener paz y yo no? [Sale por entre el público repitiendo su murmullo.] ¡Caridad... Cordelia... Caridad... Cordelia... Caridad... Cordelia...! (Trece apuestas 179).

El tono del parlamento de Millonario verdadero en este fragmento sugiere que está en fase de negación de su estado mental. Declara además que, según él, no es locura la hiperrealidad que ha creado. Sin embargo, admite que le provoca miedo enfrentar la verdad que pueda revelar y "perder la razón como Lear" (ibídem). Millonario verdadero mezcla diálogos de Shakespeare con sus propias declaraciones, diluyendo así los límites entre la realidad y la ficción y creando su simulación de la realidad o -como le llama Baudrillardhiperrealidad. La realidad, para este personaje en la obra de Schmidhuber, se revela al final de la obra, cuando el espectador conoce por fin la identidad de quien ha creado todos los planos interiores de la pieza: Álvaro, el dramaturgo textual del marco teatral real. Al negar su presente estado mental, Millonario verdadero bifurca su identidad confundiéndola con la del Rey Lear, adoptando su papel y recitando sus parlamentos.

Según Baudrillard, el acto de simular es fingir lo que uno no tiene; la simulación amenaza la diferencia entre lo verdadero y lo falso, lo real y lo imaginario (3). Con la confusión de identidad de Millonario verdadero, el dramaturgo plantea que la distinción entre la realidad y la ficción es turbia. Schmidhuber establece, en Todos somos el rey Lear, la evolución que tendrá el personaje Millonario en una nota al principio de la obra: "pasa de ser el único público a dirigir la escena, luego a ser actor y, por último, es personaje" (Trece apuestas 156). Sus transformaciones marcan las transiciones entre los distintos planos de realidad en la obra. Este tipo de transformaciones las sugiere y explica Octavio Paz:

La simulación es una actividad parecida a la de los actores y puede expresarse en tantas formas como personajes fingimos. Pero el actor, si lo es de veras, se entrega a su personaje y lo encarna plenamente, aunque después, terminada la representación, lo abandone como a su piel la serpiente. El simulador jamás se entrega y se olvida de sí, pues dejaría de simular si se fundiera con su imagen. Al mismo tiempo, esa ficción se 
convierte en una parte inseparable -y espuria- de su ser: está condenado a representar toda su vida, porque entre su personaje y él se ha establecido una complicidad que nada puede romper, excepto la muerte o el sacrificio. La mentira se instala en su ser y se convierte en el fondo último de su personalidad (37-38).

Esta transmutación de la vida a su teatralización, sugerida teóricamente por Octavio Paz, es precisamente lo que ocurre con Millonario en la obra de Schmidhuber. Así, lo que ofrece el dramaturgo de Todos somos el rey Lear es un theatrum mundi virtual, donde la división entre ser espectador y ser actor, la observación y la participación, pasan de la vida a su puesta en escena. Millonario y, luego, Álvaro (de 50 años) son los espectadores y los autores de sus respectivas proyecciones dramáticas; el personaje Rey Lear de Shakespeare es quien ayuda a instruir a ambos a superar las consecuencias de los errores cometidos en su vida. Como explica Jones, "[e]n la dramaterapia el paciente puede servirse de un texto existente o de su propio libreto. Éstos son trabajados de manera que el cliente pueda encontrar sus propias asociaciones, significados o interpretaciones" (153). ${ }^{12}$

En la última escena de la obra, la acción pasa del plano 2 -o sea el nivel hiperreal de $\mathrm{Mi}$ llonario- a otro plano hiperreal, consistente en Álvaro -ya con la edad que tenía su padre en el plano teatral anterior- reflexionando y explicando cómo se llegó a la creación de esta obra y su puesta en escena. Empleando los conceptos de Baudrillard, este último plano sería el marco hiperreal de la obra de Schmidhuber. La posibilidad de este otro nivel se había sugerido sutilmente al principio de la obra, al observarse que Sergio no se había memorizado el papel de Lear, mientras que su hijo, Álvaro, indicaba estar muy cómodo con el mismo. Sin embargo, el hijo no se había adentrado en el papel que se le había asignado, el bufón de la obra de Shakespeare (Trece apuestas 164). El valor simbólico de este hecho es de considerarse, tomando en cuenta que, al final de la obra, se revela que Álvaro mismo es quien había estado ejerciendo auto-terapia por medio de la escenificación teatral de Todos somos el rey Lear. De esta manera, el dramaturgo pone de relieve lo que el público y los supuestos compañeros actores descubrirán más tarde: el hecho de que se ha creado todavía otro nivel de simulacro o, mejor dicho, el marco hiperreal de la obra. El espectador ha presenciado la realización del theatrum mundi, aquel que va al estilo de Bertolt Brecht, Samuel Beckett y Antonin Artaud.

Según Baudrillard, la representación y la simulación no son conceptos intercambiables. Él mantiene que la representación del signo y lo real son equivalentes en la primera etapa de la representación, mientras que en la simulación cualquier valor referencial del

12 In dramatherapy, clients can use an existing text or create their own script to work from. These are worked with so that the client can find their own associations, meaning or interpretation. 
signo a lo real, pasa de ser una distorsión de la realidad a una anulación completa de ella en la cuarta etapa (6), lo cual equivaldría al marco hiperreal en el presente estudio.

Las acotaciones que acompañan el comienzo de este nuevo plano del marco hiperreal al final de la obra de Schmidhuber son las siguientes: "Hemos abandonado el teatro realista y, por unos instantes, incursionamos en el teatro fantástico. El físico es de Sergio, pero los movimientos recuerdan al que antes fuera el joven Álvaro. [...] Es Álvaro de cincuenta años y el actor que ha representado hasta este momento su padre, Sergio [sic]" (Trece apuestas 181). Por lo tanto, lo que se tiene en esta obra es una simulación o negación de lo real por medio del simulacro.

A manera de explicación de su presencia en este nivel hiperreal, haciendo el papel de su propio padre, Álvaro revela:

Hace muchos años que sucedió lo que han visto. Le pasó a mi padre. Yo soy Álvaro, y tengo la edad que mi padre tenía entonces. [...] Se equivocó como el Rey Lear y como el Millonario, escogió a la hija equivocada, y ella se convirtió en una mezcla de Gonerilda y Regania $[. . .]_{¡}$ Todos vivimos el drama y la tragedia de nuestra fragilidad! Por eso podemos decir, con el ánimo pleno de esperanza, que en lo más íntimo de nuestro ser: Todos Somos El Rey Lear [sic] (Trece apuestas 181-182).

Con estas palabras, Álvaro reflexiona, disculpa los errores cometidos por su padre y, sin embargo, llega a la conclusión de que todo humano es capaz de cometer los mismos errores al declarar: “Todos Somos El Rey Lear [sic]" (Trece apuestas 182). El proceso de simulacro y creación de hiperrealidad ha sido, entonces, terapéutico para Álvaro y aun tal vez para el dramaturgo mismo y para el público. Al escuchar una versión más corta de este trabajo en el Coloquio de Teatro Latinoamericano que tuvo lugar en la Universidad Iberoamericana de la Ciudad de México en noviembre del 2014, Schmidhuber mismo -quien estaba presente- le compartió a la presente autora que por medio de esta obra él había explorado su identidad como dramaturgo. Por medio de este ejercicio creativo de construir múltiples planos de realidad e hiperrealidad, el autor llega a la esencia de su propia dramaturgia y de su íntimo proceso de escribir teatro. Esta obra es el "hijo" del autor y para llegar a conocerlo a fondo tuvo que participar en una auto-reflexión a pesar de los obstáculos o retos que esto le hiciera enfrentar; o sea que el dramaturgo mismo vivió un proceso de drama-terapia. El autor de Theatre for Change identifica así a la drama-terapia:

La dramaterapia [...] es la aplicación de una o más formas de drama y teatro a personas que buscan explorar problemas personales y colectivos, así como tomar acción 
hacia el cambio. [...] Las formas de drama y teatro pueden incluir, pero no se limitan a: juego libre, improvisación, narración, composición de relato, juego de rol, manejo de marioneta y máscara y la representación teatral (Landy, 171). ${ }^{13}$

Si se considera cada momento en que algún personaje de Todos somos el rey Lear lucha para hacerle frente a alguna verdad por medio de la simulación, se descubre que son quizás síntomas del esfuerzo de Schmidhuber para definir su auténtica identidad como dramaturgo. Cada simulación es entonces proyección dramática del dramaturgo. Él y su personaje Álvaro son uno y el mismo.

Cabe hacer memoria aquí de un pensamiento ya citado antes, de Octavio Paz: "Simulando [...] el gesticulador [...] se funde con sus gestos, los hace auténticos" (36). Así, Schmidhuber, al simular la hiperrealidad de Álvaro, se funde con sus propios matices como dramaturgo. Aplicando aquí conceptos sobre la transformación en la dramaterapia, que indican que los eventos reales de la vida se transforman en representaciones de los mismos, la representación de la escritura dramática es el ejercicio que le permite a Schmidhuber explorar y descubrir su propia estética teatral.

Álvaro, elaborando sobre el género del teatro, afirma:

¡El teatro debe perdurar por una razón: porque la humanidad aún no ha aprendido a no equivocarse! Pasan miles de años y los hombres volvemos a cometer los mismos errores, una y otra vez; porque la esencia del hombre está en decidir, y decidir es arriesgarse a errar. ¡Por eso el teatro es un homenaje a la libertad y un canto a la humana tontería!" (Trece apuestas 182).

Este parlamento de Álvaro refleja la visión dramatúrgica de Schmidhuber mismo, quien recordando un consejo que le dio Rodolfo Usigli afirma en El ojo teatral que su mentor le retó a arriesgarse al teatro durante toda su vida (El ojo teatral 193). Así, el simulacro sobre el que teorizaba Baudrillard es el teatro mismo en Schmidhuber. Además, el simulacro y la creación de una hiperrealidad con El rey Lear de Shakespeare sirvieron de ímpetus para la exploración teatral del autor mexicano.

En su simulación de Lear, Schmidhuber destaca a la dramaturgia como medio de reflexión y exploración de conflictos interiores que inquietan a todo humano. Al incluir re-

13 Drama Therapy [sic] is the application of one or more forms of drama and theatre to people who choose to explore personal and collective problems and to take action toward change. [...] The forms of drama and theatre can include, but are not limited to: free play, improvisation, storytelling and story-making, role-playing, puppetry and mask, and theatre performance. 
ferencias intertextuales a Shakespeare y su Rey Lear, así como a Segismundo de La vida es sueño de Calderón de la Barca (Trece apuestas 175) y a piezas de vodevil (Trece apuestas 174), Schmidhuber subraya la teatralidad de la existencia humana, pero ofrece también otros ejemplos donde se han creado realidades alternas o distorsiones de la realidad por medio de la dramaturgia. En Todos somos el rey Lear, Guillermo Schmidhuber plantea las "cajitas chinas" como exploración de multiplicidad de niveles de representación y, además, contribuye con varias propuestas sobre el teatro mismo. Hacia el final de la obra, al revelar sus pensamientos sobre Sergio, el Actor de millonario ofrece una serie de afirmaciones sobre el género teatral. Por medio de las palabras de este personaje, el dramaturgo indica: "El teatro no es ejemplar. El teatro solamente nos permite adentrarnos por un instante en el misterio de la libertad humana, y comprender un poco más de la condición temporal de la humanidad" (Trece apuestas 175). El dramaturgo señala al teatro como medio para explorar el ser interior y -empleando terminología de la dramaterapia- como ejercicio dramático que lleva hacia alguna transformación ya sea humana, del actor, del espectador o del dramaturgo mismo. Posterior a un parlamento de Millonario verdadero, Sergio entabla su propia enunciación en la que habla sobre ser actor y sobre el teatro: "El teatro no es un pasatiempo, es una búsqueda conjunta del autor, el director, los actores y el público de una verdad interior" (Trece apuestas 180). En la obra de Guillermo Schmidhuber, los personajes Millonario verdadero y Álvaro intentan enmendar los conflictos vitales que les inquietan por medio de proyecciones dramáticas terapéuticas, pero su exploración se extiende también al autor de Todos somos el rey Lear cuando éste negocia sus inquietudes dramatúrgicas al escribir la obra.

\section{Fuentes consultadas}

Baudrillard, Jean. Simulacra and Simulation. Michigan: The University of Michigan Press, 1994.

Jones, Phil. Drama as Therapy: Theory, Practice, and Research. Volume I. Londres/ Nueva York: Routledge, 2007.

Landy, Robert J. and Montgomery, David T. Theatre for Change: Education, Social Action and Therapy. Nueva York: Palgrave MacMillan, 2012.

Paz, Octavio. El laberinto de la soledad. México: Fondo de Cultura Económica, 1989.

Schmidhuber de la Mora, Guillermo. El ojo teatral. Guanajuato: Ediciones La Rana, 1998.

Schmidhuber de la Mora, Guillermo. Trece apuestas al teatro. Volumen Segundo. México: Universidad de Colima, 1999.

Shakespeare, William. The Complete Works of William Shakespeare. Nueva York: Gramercy Books, 1975. pp. 973-1009. 